\title{
Performance Skills of Piano Music Scene from Childhood
}

\author{
Hui Chang \\ Music and Dance Institute, Beifang University of Nationalities, Yinchuan, 750021, China
}

\begin{abstract}
Keywords: Schumann, piano music, Scene from Childhood, Performance skills
\end{abstract}
\begin{abstract}
Schumann music is closely correlated with literature and poetry. A solid literary foundation also becomes a basis for his engagement in music. By virtue of this unique artistic foresight, he continuously dug new stars, never agreed with social corruption and rebuked decadent and declining social thought, making significant contributions to the development of European music undertakings. Under extensive life and creation experiences of Schumann, many energetic music works were created. In this paper, the author stated and analyzed music features of Schumann's piano music works and performance skills of Scene from Childhood. At last, the author proposed relevant enlightenments to piano teaching in China.
\end{abstract}

\section{Preface}

Schumann read many famous literary works, so he has a profound literary foundation. 13 remarkable songs in Scene from Childhood describe diversified stories with distinctive colors, representing beautiful memory of adults and their yearning for their childhood. Viewed from its development course, piano has a history of more than one hundred years in China. However, its development momentum in China's music circle cannot be overlooked. With the introduction of piano, more and more people recomposed traditional music works into piano music, increasing the significance for research on the piano music Scene from Childhood.

\section{Musical features of Schumann's piano music}

A simple, subtle and profound mood is one of features of Schumann's art songs. Schumann melody is just like a recited song. Drama structure is used to give expression to unique variability of music. Processing of subtle tone enriches the expression of its thought. A distinctive contrast is presented between passionate and restrained emotions. Schumann's music is always subtle with distinctive features, like a passionate and roaring lion. Main features can be divided into the following aspects:

\section{Personal character drawn with interlaced music and literature}

Music songs performed by Schumann are of great imagination and integrated with French style romance. Passion is another feature of his music, playing an important role in promoting the world romantic music onto a new stage. Butterfly in A Masked Ball is one of Schumann's masterpieces. Each note is properly integrated, representing inherent personality of soul and deep thought of musical expression. To some extent, Dances of the League of David is used as his auxiliary work to express his disgust with corruption and philistinism. Scene from Childhood vividly presents middle-aged people's endless yearning for their childhood. Featured characters in Carnival give full expression to profound artistic foundation of Schumann.

\section{Representation and existence of music as the most direct point of venting}

Among piano works in the $19^{\text {th }}$ century, Fantasy in C Major is a piece of venting work created by Schumann in the period of his life valley. Typical romantic color is integrated with emotional venting, giving full expression to Schumann's innermost feelings. For this piece of song, ballade, sonata, partita and other musical features are integrated in the first chapter. It seems separated. Actually, it is united. This new mode of organization has profound influence on overall arrangement of Polonaise Fantaisie, The Fourth Ballade, and others. 


\section{Precise polyphony organization}

Polyphony and line are fundamental thrust of works performed by Schumann. In his works, he paid attention to the first line of each internal organization, full of harmonious sounds of different kinds of music. Schumann not only emphasizes expression of piano performance skills but also integrates width features of melody interzone. According to the author, among all composers influenced by Bach, Schumann has the most considerate consideration of chord. He abandoned external vanity. At the same time, he is also ranked among world romantic composers.

\section{Performance skills of the piano music Scene from Childhood}

Integration scenario is represented in music. This is the highest state of music performance. Chinese traditional music is mainly featured by "linear thinking". It is different from "vertical thinking" of western music including piano. This a key influence factor in the process of piano recomposing Chinese instrumental music. Based on better processing of melody as well as wide range, degree of enrichment and other features of piano, composers can reconcile instrumental music, making horizontal melody and vertical harmonic to be perfectly combined with each other. Performance features of the piano work Scene from Childhood are shown as follows:

\section{Melody features of the work}

Melody of Schumann's works is mainly structured by upright 2/4/8 phrases. Piano tone in the middle part forms calmness, representing warn and subtle lines. It is as interesting as "poem recitation”. Constantly changing mode avoids boringness to the maximum extent. Diversified colors further deepen audiences' impression. Sleeping Child is a typical sound-type representative. Both left and right hands adopt the method of 8 in the front and 16 in the rear. Rear dots are used for sound-type melody. No matter in Phrases A or B, the left hand is still for sound-type melody. However, rear dots become small segmentation. This mode perfectly presents safe states of sleeping children. It is of a strong sense of picture.

\section{Rhythm features of the work}

Alternation of rhythm and rhythm stress presents the feature of strong restlessness. Duple and triple beats are the most common in Scene from Childhood. Triple beat stands for flexibility, and duple beat symbolizes proceeding romantic charm. Segmentation and dot rhythm are the most obvious features, including front \& rear dots and deformation. A Strange Story is a typical work of the feature of dot. Both hands start from the same rhythm at the same time. Small dot eighth note becomes a pause, almost perfectly presenting children's curiosity about new things. A Game of Wooden Horse and Too Earnest are typical works of segmentation rhythm. The latter begins to become weak from the right hand. In this piece of work, continuous segmentation is used to present the features of melody. Connected lines are formed from the tail of each phrase to the beginning of the next phrase.

\section{Harmonic features of the work}

Frequent use of transposition chord will produce the effect of harmonic external sound. Expansion of external sound makes music to be dimly discernible. Regret harmony is the biggest feature of Scene from Childhood. It has unique charm of regretful harmony. At the end of Scene from Childhood, three songs are obviously subject to harmonic regret processing, including Sleeping Child. E minor is adopted in the entire song. At the end, it doesn't center on primary chord. Instead, it gets close to subordinate chord. It gives an infinite feeling, almost perfectly presenting the real existence of a sleeping child.

\section{Analysis on performance of Scene from Childhood}

\section{About Strange Lands and People}

For the background of this song, the middle part is used to set off by contrast the primary melody. Continuous tercets should be evenly and skillfully performed. For eighth note in the soft voice part, 
fingertip should touch the key. It should be performed like plucking in string music, making it to give full play to the effect of harmony.

\section{A Strange Story}

Rolling of the first beat and playing of the third beat are of great importance. The first beat should be light and flexible, like chatting between two persons. The wrist should be lifted for light expression. For modified sound, fingers should be placed as low as possible. When four times of rolling appear alternatively, it should be gradually strengthened, till the fourth group of stress is over.

\section{Hide-and-Seek}

Children's playing scenes are presented by pause of fingers back and forth. In the performance process, don't neglect the function of facial expression. After sudden increase, there should be a sharply weakening moment. Jumping sound should be flexible, so as to highlight unique particles. After loosening of forearm, the advantage of fingertip should be used to make quick response. Stress of index finger and little finger should be expressed in place, with particular attention paid to the speed of four fingertips. The sliding distance is long for the left hand, and it is also very difficult. At this moment, we should highlight the importance of radical and master the gravity of finger.

\section{A Child's Request}

In the performance process, attention should be paid to fluency of melody phrases in the high part. Jujube type melody fluctuation should be made, if necessary. Pay attention to the speed of the entire song as well as beautiful posture when both hands are in the middle part; take advantage of the wrist; obvious difference should be highlighted for left hand radical. However, finger prominence should be slow and gentle.

\section{Satisfaction}

Performance should be thick and solid with resonance. Pay attention to emotional control. After slowing for a second time, Major D should transfer to Major F, presenting the climax by lifting up three dimensions, and highlighting the player's happiness. Pay attention to the strength of finger mainly focused on melody, give play to fingertip advantages, hold the key, close to the key during a double-note, and have proper control over the entire song.

\section{An Important Event}

In the performance process, pay attention to us of little finger and left hand, maintain smooth lines of melody, conform to the integration feature of right hand melody, accurately express dot rhythm, avoid the occurrence of jump of stress, and performance should be decisive. Left hand in Phrase B shows primary melody. The first phrase and the first note should be properly expressed. For octave high pitch performance, attention should be paid to the importance of palm supporting. Forearm should be flexible.

\section{Fantasy}

The first phrase is mainly of key touch by finger pulp. It should be gentle and beautiful, making listeners feel as if they entered a dream. The second phrase should be strengthened. Too fast performance is not recommended. Footstep should be used to enrich harmonic color belonging to melody. For the third phrase, Minor g should be used to create a tense feeling. For the fourth phrase, descending Major B should be used. Regretful emotions should be distinguished from happiness expressed in the beginning.

\section{Aside the Furnace}

In the performance process, pay attention to the function of right hand used to control melody. Left hand radical should be properly expressed. Emphasis should be laid on Phrase B. Radical should be continuous, and it is over by the next chapter. Pay particular attention to the fact that sound phrase of little finger should couple hardness with softness and auxiliary melody should be placed in the principal position. This song is of great span, with distinctive contrast between high part and low part. In the middle part, clearness of melody should be properly controlled.

\section{A Game of Wooden Horse}

In the performance process, the right hand should be independent. Thus, stress should not be too heavy. For the middle part, sustained tone appearing in the low part should be emphasized. Key touch should be flexible, give play to the advantage of fingertip, and get close to the key; from 5 to 8 
sections are divided as the second phrase. Melody in the middle part is mainly expressed by the left hand. Movement of finger should be partial to expression of the middle part. Radical should be maintained the same. Both items should be distinguished from each other. Radical descending of the left hand should be based on 9-16 sections. However, for radical at the $13^{\text {th }}$ section, left hand descending should be used to achieve the purpose of octave jump step by step before the arrival of the climax.

\section{Too Earnest}

Beat fluency is a precondition for performance of this song. Pay attention to lengthening of phrase and lowering down of note, properly master the lengthened time, definitely mark the pause between it and the next phrase, control pause as "breath"; the same as the background of a picture, low part renders children's facial expressions, and sets off by contrast the atmosphere.

\section{Scare}

Melody of this song starts from and ends at the right hand. The left hand is used for semitone descending in the tense phrase, as if the demon in the fancy world entered the room in silence and was ready to capture children. Then, weak beats in Phrase B should be stressed, breaking through rhythm melody of traditional 4/2 beat, so as to present children's fear while being suddenly scared.

\section{Fall Asleep}

Melody in Phrase A is based on and developed by centering on b tone, the same as a mother's singing a song. In the performance process, pay attention to weak tone, properly master eight dotted notes like a conversation, "push" back and forth on the keyboard with the little finger, and the scene of crossing hands is used to perform the beauty of flexible melody.

\section{A Poet's Words}

In the performance process, pay attention to stability of chord in this part, press down after getting well prepared, give full expression to the position of high sound, the phrase is of fluctuation; it is less for Phrase B, only accounting for a single phrase. However, it uses a different way to express the melody, with strong musical expressive force. This part belongs to expression of the writer's innermost feelings. In the performance process, the players should carefully play each note, and present its unique charm.

\section{Enlightenment to piano teaching in China}

Guide the students to master creation background and emotional expression of musical works, guide them to carefully appreciate poetic imagery beauty of the works, pay attention to training of performance skills. These are three enlightenments for piano teaching in China. Compared with western piano education, China started relatively late in this aspect. Moreover, China also lacks representative piano music works. Therefore, western music works are used as main textbooks in China's piano teaching, including Beethoven, Chopin and Schumann. When students' skills reach a certain degree, however, they will contact Chinese instrumental music works, more or less. At this time, they are easily influenced by performance thought and habit of western music, leading to incomplete expression to traditional national features in Chinese instrumental music. In the process of recomposition or performance, serious “distortion” is led. Due to diversified Chinese traditional instruments, any piece of piano music recomposed from traditional instrumental music has differences in each ornamental tone, especially when an ornamental tone appears in several parts of a song. Its performance and speed will not follow the natural mode. At this moment, performers should have sufficient understandings of will and emotional expression of the original music and get familiar with tone characteristics of the original musical instrument, so as to finish musical creation in a better way. This also provides guidance to piano teaching in China.

\section{Conclusion}

Innovation of this paper lies on its combination of theory with practical performance skills, so as to allow everyone to know Schumann and his work Scene from Childhood. It is also rich in expression 
and imagination. Additionally, Chinese piano recomposition is an important channel for integration and exchange between Chinese and western musical culture. At the same time, it is also inheritance and development of Chinese traditional music culture. In the performance process, we should be based on emotional expression and artistic features of the original works, skillfully master pattern of manifestation of ornamental tone in piano music recomposition, and give proper expression to emotions of the original works in recomposed works. During teaching activities, we should regard above points as emphasis of teaching, pay attention to training of students' basic performance skills, and give full play to recomposed piano music works, so as to lay a solid foundation for good inheritance of Chinese music culture, make Chinese traditional music culture have better inheritance and development, and achieve the purpose of piano cultural communication of "making innovations based on classics”.

\section{References}

[1] Tan Jianguang, Discussion on Romantic Features of Schumann's Scene from Childhood, People’s Music Publishing House, 2013 (05): 38-40;

[2] Written by (American) Greutert and Palisca and translated by Wang Qizhang, Wu Peihua and Gu Lianli, Universal History of Music, Beijing: People’s Music Publishing House, 2011: 12-15;

[3] Barbera Mayer, Robert Schumann, People’s Music Publishing House, 2014 (06): 02-05;

[4] Yang Lili, Research on National Features of Chinese Piano Music Recomposed by Wang Jianzhong, Journal of Changzhou Institute of Technology (Social Science Edition), 2013 (03): $52-57$ 